\title{
Simultaneous qualitative and quantitative analysis of Tangkening granule using thin layer chromatography (TLC) and high performance liquid chromatography (HPLC)
}

\author{
Qiang Yuan, Lan He and Lei Mao \\ College of Pharmaceutical Sciences, Zhejiang Chinese Medical University, Hangzhou, China.
}

Accepted 13 July, 2011

\begin{abstract}
This study was designed to establish the quality standard of Tangkening granule in order to effectively control the quality of this new Chinese traditional patent medicine in the process of production, in addition to ensure the good clinical application. Fructus gardenia, Herba gynostemmatis, Dioscorea batatas, and Polygonatum odoratum in Tangkening granule were identified by thin layer chromatography (TLC), and the content of geniposide was determined by high performance liquid chromatography (HPLC). A comprehensive validation of the method that included sensitivity, linearity, repeatability and recovery was conducted. The results show that this analytical method was simple and suitable for the original identification and quality control of this new Chinese traditional patent medicine.
\end{abstract}

Key words: Tangkening granule, geniposide, quality standard, thin layer chromatography, high performance liquid chromatography.

\section{INTRODUCTION}

Traditional herbal medicines are usually prepared from various herbs, and they exhibit various therapeutic effects with a complex of multiplicity components (Normile et al., 2003; Xia et al., 2010). In spite of the presence of known antidiabetic medicine in the pharmaceutical market, there is growing interest in herbal remedies due to the fact that synthetic drugs lead to undesirable side effects. The search for effective and safer antidiabetic plant drugs is thus of great importance. Tangkening granule is a new preparation of an empirical prescription to treat diabetes by modern pharmaceutical technology, which is obtained from Linyi $\mathrm{Ge}$, a national famous doctor of Zhejiang Province hospital of traditional Chinese medicine (TCM).

*Correspondence author. E-mail: yuanqiang0825@sina.com Tel: +8657186613778.

Abbreviations: TLC, Thin layer chromatography; HPLC, high performance liquid chromatography; TCM, traditional Chinese medicine.
The prescription consists of Chinese herbal medicine as Fructus gardeniae, Herba gynostemmatis, Dioscorea batatas, Polygonatum odoratum, etc.

The main functions of Tangkening granule are clearing away heat, invigorating blood circulation, as well as strengthening spleen and eliminating turbidness. Clinical application showed that the prescription has not only reduced blood glucose and blood lipid concentrations, but also reduced insulin resistance and enhanced insulin sensitivity. In addition, it has unique curative effect for the treatment of type-2 diabetes (Zhang et al., 2009).

$F$. gardeniae is the main drug in Tangkening granule, and it has the effects of purging pathogenic fire and eliminating restlessness, clearing heat and promoting diuresis, cooling blood and detoxication. Geniposide is an iridoid glucoside which is extracted from $F$. gardeniae. Several reports have reported that geniposide was an effective hypoglycemic agent in HFD-STZ-induced diabetic mice (Wu et al., 2009; Huang et al., 2006). This compound has been shown to possess anti-diabetic (Kimura et al., 1982), anti-inflammatory (Koo et al., 2004), detoxifying (Kuo et al., 2004), anti-oxidative (Pharm et al., 
2000) and anti-angiogenic functions (Park et al., 2003). The first report of its hypoglycemic activity in high sugar diet-induced diabetic mice was made in 1982 (Kimura et al., 1982). Recent studies further confirmed the hypoglycemic effects of geniposide and genipin, an aglycone of the enzyme-hydrolytic geniposide (Yan et al., 2007; Zhang et al., 2006). Thus, this study aimed to establish the quality standard of Tangkening granule. The identification of Fructus gardeniae, Herba gynostemmatis, and Dioscorea batatas was done using thin layer chromatography (TLC), and the determination of geniposide content was done using high performance liquid chromatography (HPLC) (Guo and Lin, 2007; National Pharmacopoeia Committee, 2005; Xu and Pan, 2005).

\section{MATERIALS AND METHODS}

\section{Apparatus}

Waters 510 HPLC, analytical balance (Sartorius, Germany) and R204 rotary evaporator from Shanghai SENCO Technology Co., Ltd. (Shanghai, China) were used.

\section{Reference standards}

The reference compounds of geniposide, diosgenin, and the reference materials of Fructus gardeniae and Herba gynostemmatis were purchased from the National Institute for the Control of Pharmaceutical Biological Products (Beijing, China).

\section{Solvents and materials}

Acetonitrile and methanol of HPLC grade were purchased from Tianjin SiYou Co., Ltd. (Tianjin, China). Acetic ether, formic acid, and $n$-butyl alcohol were of analytical grade. The test samples of Tangkening granule were supplied by Zhejiang Tianyitang Pharmaceutical Co., Ltd. (Hangzhou, China). The negative samples were supplied by pharmaceutic laboratory of Zhejiang Chinese University.

\section{Processing procedure of Tangkening granule}

A prescription of the medicinal herbs was extracted with 10 volume of water three times, each time for $1.5 \mathrm{~h}$. After mergering the extracting solution and filtering, filtrate was concentrated to the relative density of 1.1 . The spray drying is to control the spray speed at $30 \mathrm{ml} / \mathrm{min}$ and air-in temperature was $150^{\circ} \mathrm{C}$ for the dry powder. Then the dry powder was plused with $50 \%$ dextrin and $2 \%$ xylitol by thorough incorporation, and sprayed with $85 \%$ ethanol, granulated, dried, pelletized, and dispensed for each bag of $20 \mathrm{~g}$.

\section{TLC identification}

\section{Fructus gardeniae}

The powdered sample of Tangkening granule $(3 \mathrm{~g})$ was extracted with $20 \mathrm{ml}$ of ethanol for $40 \mathrm{~min}$ by sonication. After filtration, the filtrate was concentrated to $10 \mathrm{ml}$ as the TLC test solution in a water bath. Geniposide (10 mg) was accurately weighed, placed into 10 $\mathrm{ml}$ volumetric flask, diluted with ethanol to volume, and mixed to make standard solution. The negative sample (the negative solution) without $F$. gardeniae $(3 \mathrm{~g})$ was prepared by the same method as the test solution. Pipette of the above three solutions (4 $\mu$ l) respectively, were spotted on the same silica gel $G$ thin layer plate. Ethyl acetate: acetone: formic acid: water $(5: 5: 1: 1)$ was chosen as the solvent system for TLC separation. After developing over a path of $10 \mathrm{~cm}$, the plates were air-dried, sprayed with $10 \%$ $\mathrm{H}_{2} \mathrm{SO}_{4} / \mathrm{EtOH}$, heated at $105^{\circ} \mathrm{C}$ for $10 \mathrm{~min}$, and then imaged immediately under visible light.

\section{Herba gynostemmatis}

The powdered sample of Tangkening granule $(3 \mathrm{~g})$ was extracted with $20 \mathrm{ml}$ of methanol for $40 \mathrm{~min}$ by sonication. After filtration, the filtrate was quickly dried in a water bath. The residue was dissolved in $5 \mathrm{ml}$ of water and extracted with ether twice, and then the ether layer was thrown away. The water layer was extracted with $n$-butyl alcohol three times. Then the $n$-butyl alcohol layer were mixed and dried in a water bath. The residue was dissolved in $2 \mathrm{ml}$ methanol as the TLC test solution. The reference material of $H$. gynostemmatis $(2 \mathrm{~g})$ and the negative sample without $H$. gynostemmatis $(3 \mathrm{~g})$ were prepared with same method as the test solution into standard solution and negative solution respectively. Pipette of the above three solutions $(4 \mu \mathrm{l})$ respectively, were spotted on the same silica gel $\mathrm{G}$ thin layer plate. $\mathrm{N}$-butyl alcohol: ethyl acetate: water $\left(4: 1: 5\right.$, the upper layer under $\left.10^{\circ} \mathrm{C}\right)$ was chosen as the solvent system for TLC separation. After developing over a path of $10 \mathrm{~cm}$, the plates were air-dried, sprayed with $10 \% \mathrm{H}_{2} \mathrm{SO}_{4} / \mathrm{EtOH}$, heated at $105^{\circ} \mathrm{C}$ for $10 \mathrm{~min}$, and then imaged immediately under visible light and UV light (365 nm).

\section{Dioscorea batatas}

The powdered sample of Tangkening granule $(3 \mathrm{~g})$ was reflux extracted with $30 \mathrm{ml}$ of $8 \%$ hydrochloric acid solution for $2 \mathrm{~h}$ and then the solution was extracted with chloroform twice, each $20 \mathrm{~min}$. The solvent was recovered from chloroform by the rotary evaporator. The residue was dissolved in $1 \mathrm{ml}$ chloroform as the TLC test solution. Diosgenin $(13.4 \mathrm{mg})$ was accurately weighed, placed into $5 \mathrm{ml}$ volumetric flask, diluted with chloroform to the volume and was mixed to make the standard solution. The negative sample without $D$. batatas $(3 \mathrm{~g})$ was prepared with same method as the test solution (negative solution). Pipette of the above three solutions $(4 \mu \mathrm{l})$ respectively, were spotted on the same silica gel G thin layer plate. Toluene:acetone (9:1) was chosen as the solvent system for TLC separation. After developing over a path of $10 \mathrm{~cm}$, the plates were air-dried, sprayed with $10 \% \mathrm{H}_{2} \mathrm{SO}_{4} / \mathrm{EtOH}$, heated at $105^{\circ} \mathrm{C}$ for $10 \mathrm{~min}$, and then imaged immediately under visible light.

\section{Assay \\ HPLC conditions}

The HPLC separation was performed on a Sino Chrom $\mathrm{C}_{18}$ column $(4.6 \times 250 \mathrm{~mm}, 5 \mu \mathrm{m})$ at the temperature of $30^{\circ} \mathrm{C}$. Solvents that constituted the mobile phase were acetonitrile-water-phosphoric acid (13:87:0.1). The flow-rate was $1 \mathrm{ml} / \mathrm{min}$ and the injection volume was $10 \mu \mathrm{l}$. The detection wavelength was $238 \mathrm{~nm}$.

\section{Preparation of standard solution and sample}

Standard stock solution was prepared by dissolving geniposide in methanol at a concentration of $2.175 \mathrm{mg} / \mathrm{ml}$. Each five 


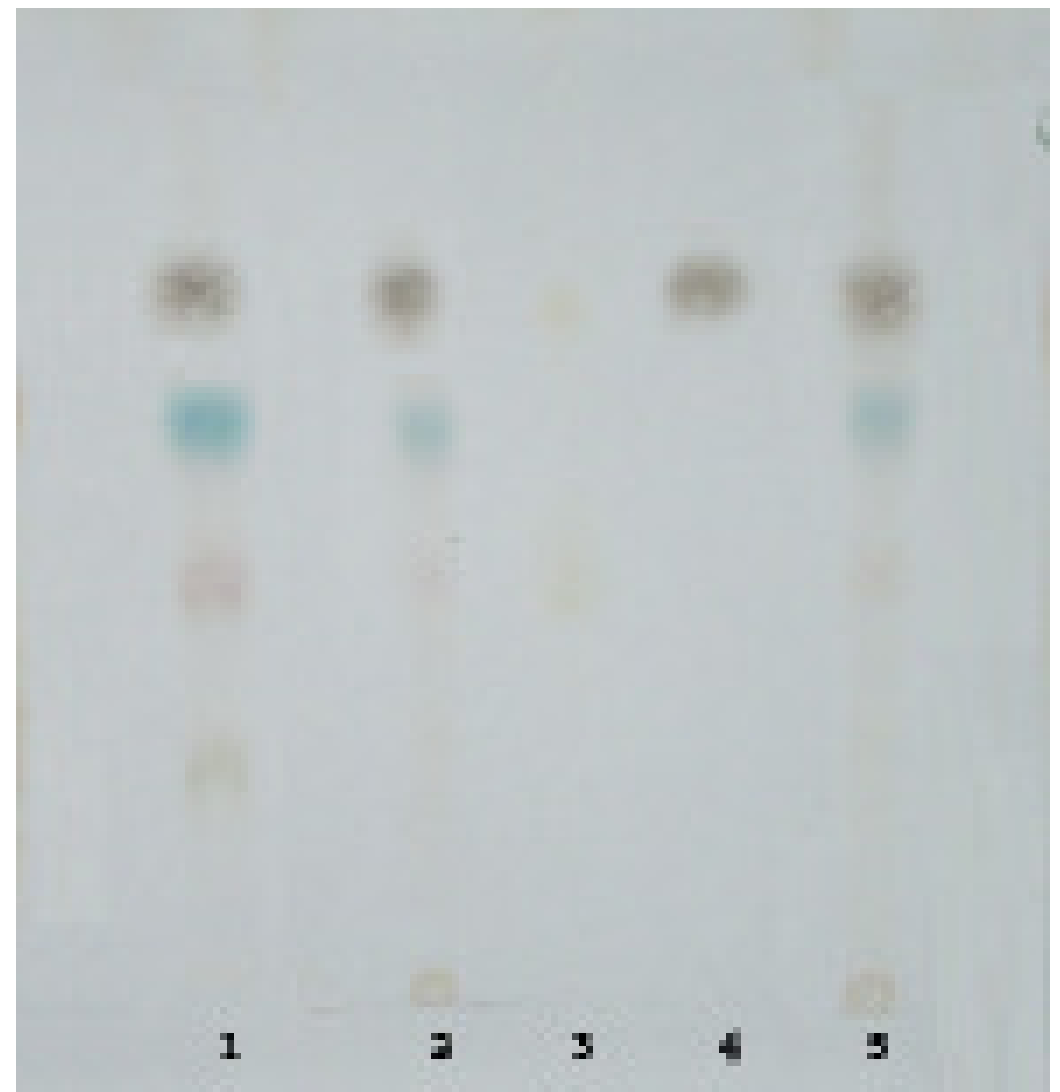

Figure 1. TLC of F. gardenia. 1, Sample of Tangkening granule; 2, reference material of F. gardeniae; 3, negative sample without F. gardeniae; 4, eference compound of geniposide; 5 , material of $F$.gardenia.

concentrations of the working solutions diluted from the stock solution were used for the establishment of a calibration curve. For the preparation of sample, $0.5 \mathrm{~g}$ of Tangkening granule was accurately extracted with $40 \mathrm{ml}$ methanol for 40 min by sonication in a $50 \mathrm{ml}$ volumetric flask, and then was diluted with methanol to the volume. The sample solution was filtered through a $0.45 \mu \mathrm{m}$ filtration film before HPLC injection. material of the prescription excluding gardenia, were weighed and prepared with the same method as the test solution to make the negative solution.

\section{RESULTS AND DISCUSSION}

The TLC results showed a good separation for the test solutions, and the reference substance in the corresponding position, which showed the same color spots. However, there was no negative interference. The spots were clear and the Rf value met requirements. That is to say, $F$. gardeniae, $H$. gynostemmatis, and $D$. batatas can be identified from Tangkening granule. (Figures 1 to 5)

\section{Optimization of HPLC extraction solvent}

Methanol, ethanol and water were selected as the extraction solvent in this study. The granule samples were extracted with $40 \mathrm{ml}$ solvent for $40 \mathrm{~min}$ in an ultrasonic bath, and the extraction solution was filtered through a $0.45 \mu \mathrm{m}$ filtration film. As a result, the maximum peak area obtained with methanol was larger than those for the other solvents.

\section{Validation of the method and quantification of geniposide}

The reference, the test and the negative solutions were respectively injected $(10 \mu \mathrm{l})$ into the HPLC. The results show that the chromatography of the test solution had the same retention time as the reference, and negative solutions did not interfere in the determination of geniposide (Figures 6A to $\mathrm{C}$ ).

The linearity of geniposide was calculated based on the five concentrations of the control. 15.3, 30.5, 45.8, 61.1 and $76.4 \mu \mathrm{g} / \mathrm{ml}$ geniposide reference solutions were prepared respectively and precisely. Then $10 \mu \mathrm{l}$ was sucked into the HPLC, the peak areas were recorded, and the standard curve was made by the injection concentration $(\mathrm{X})$ and peak areas $(\mathrm{Y})$. The regression equation is $Y=15.7928 X-84.62478, r=0.9999$; showed good linearity at a relatively wide range of concentration 


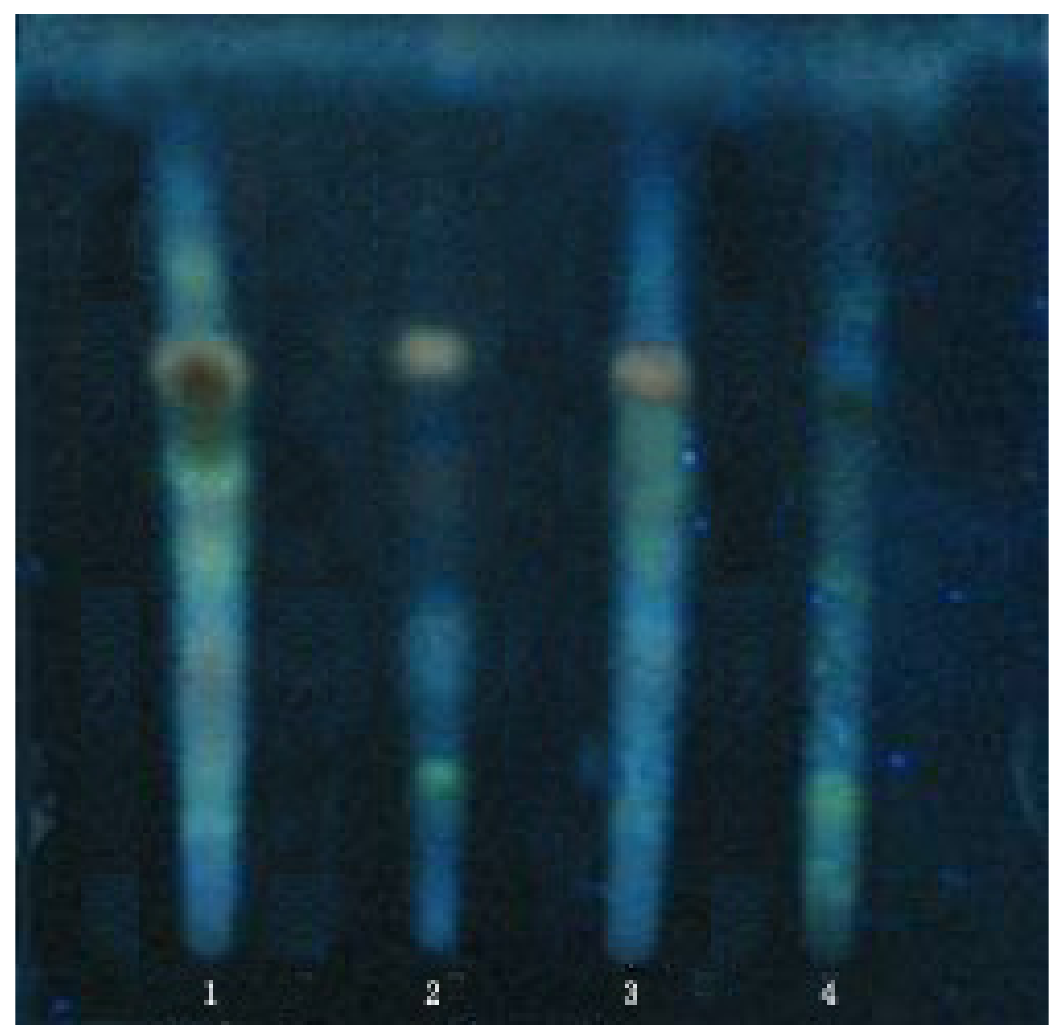

Figure 2. TLC of $H$. gynostemmatis. 1, Sample of Tangkening granule; 2, reference material of $H$. gynostemmatis; 3 , medical material of $H$. gynostemmatis; 4, negative sample without $H$. gynostemmatis.

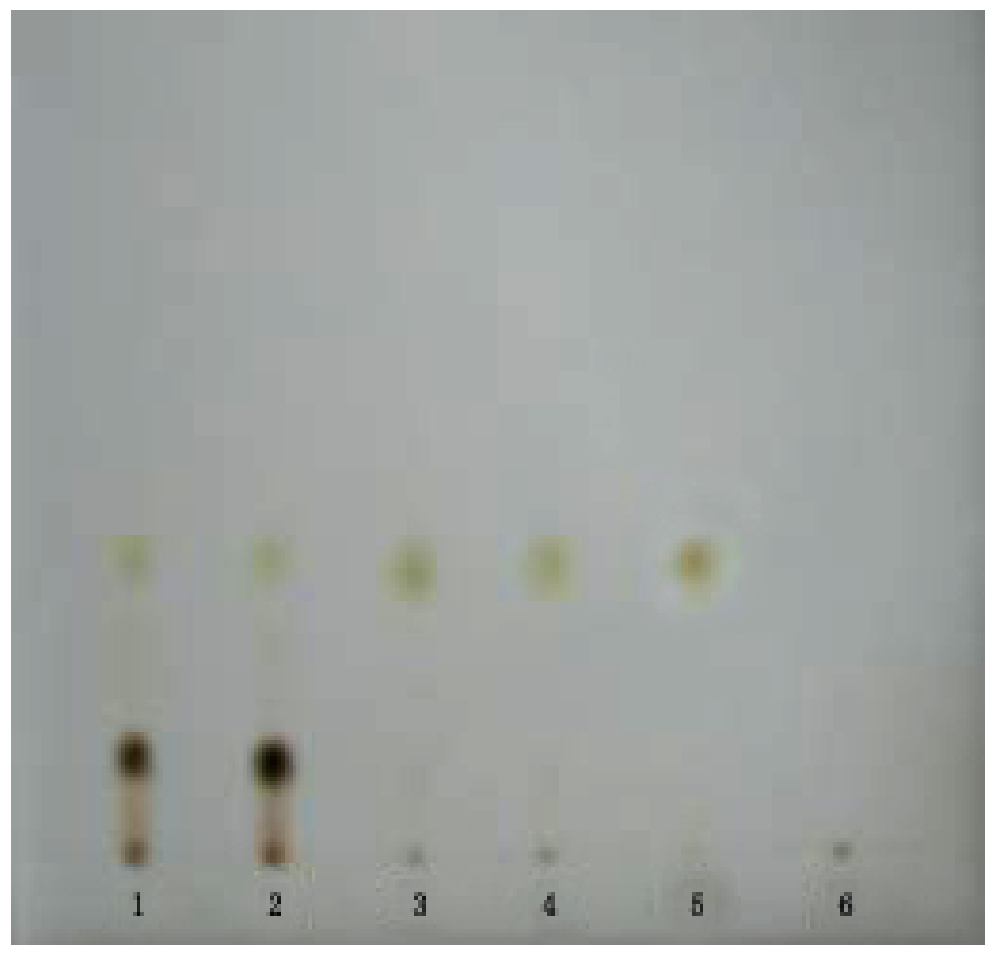

Figure 3. TLC of $D$. batatas. 1, 2. Sample of Tangkening granule; 3, 4, medical material of $D$. batatas; 5 , reference compound of Diosgenin; 6, negative sample without $D$. batatas. 


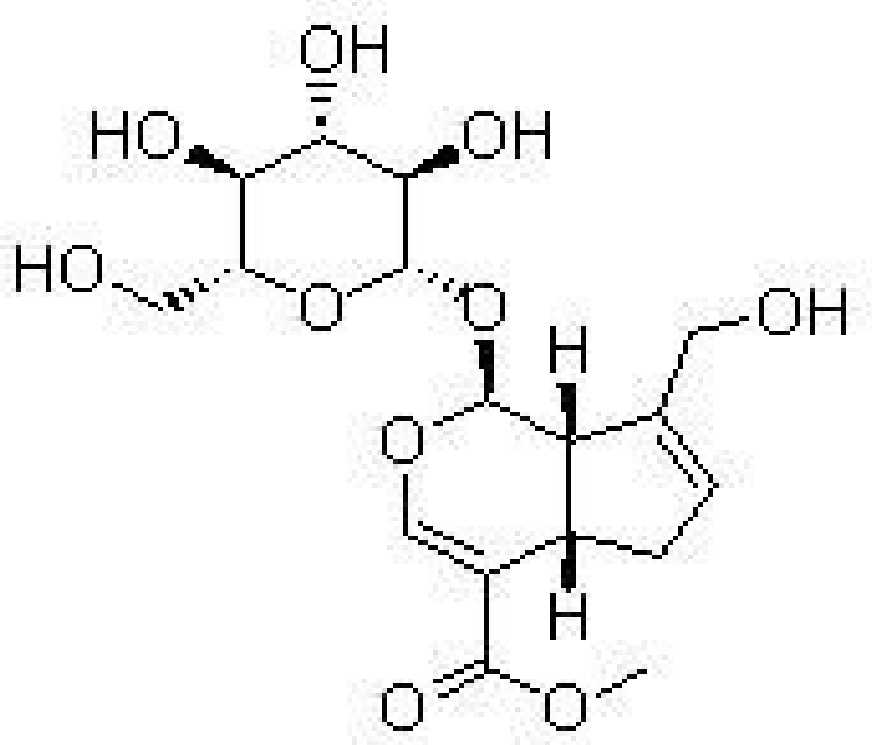

Figure 4. Structure of Gardeniae.

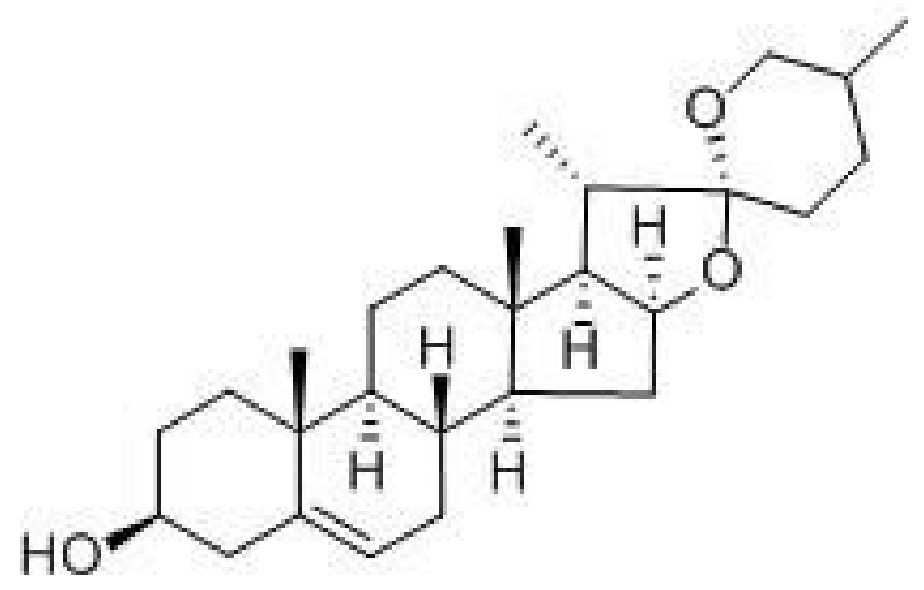

Figure 5. Structure of Diosgenin.

of 0.15 to $0.76 \mu \mathrm{g}$. The precision test was accomplished by the same concentration of geniposide. $38.2 \mu \mathrm{g} / \mathrm{ml}$ of geniposide reference substance solutions was continuously repeatedly injected 6 times; $10 \mu \mathrm{l}$ each time, determination of geniposide peak area, and RSD $0.7 \%$ $(\mathrm{n}=6)$.

The stability test (stability test solution) was according to the preparation methods of the test solution, and was then respectively determined at $0,2,4,6,8$ and $12 \mathrm{~h}$. RSD of the geniposide peak areas was $1.8 \%$, the peak areas of geniposide in $12 \mathrm{~h}$ was basically unchanged, and it showed the geniposide test solution to be stable at $12 \mathrm{~h}$ inside. The repeatability test was also according to the preparation methods of the test solution. The granule was weighed 5 times, each was $0.5 \mathrm{~g}$, the RSD value was $0.9 \%$, and this showed the methods had good reproducibility. The recovery test was validated by the method of spiked test. The accuracy of geniposide was $99.9 \%$ with RSD value of $4.82 \%(n=6)$ (Table 1$)$.

The determination of three batches of the samples was conducted as the preparation of the test solution, and was then injected $(10 \mu \mathrm{l})$, and determined (Table 2). Drugs are used to treat, prevent and diagnosis diseases, and are closely related to people's health and life safety; so it must meet the quality requirements. Chinese herbal medicine in during production, harvest and processing 

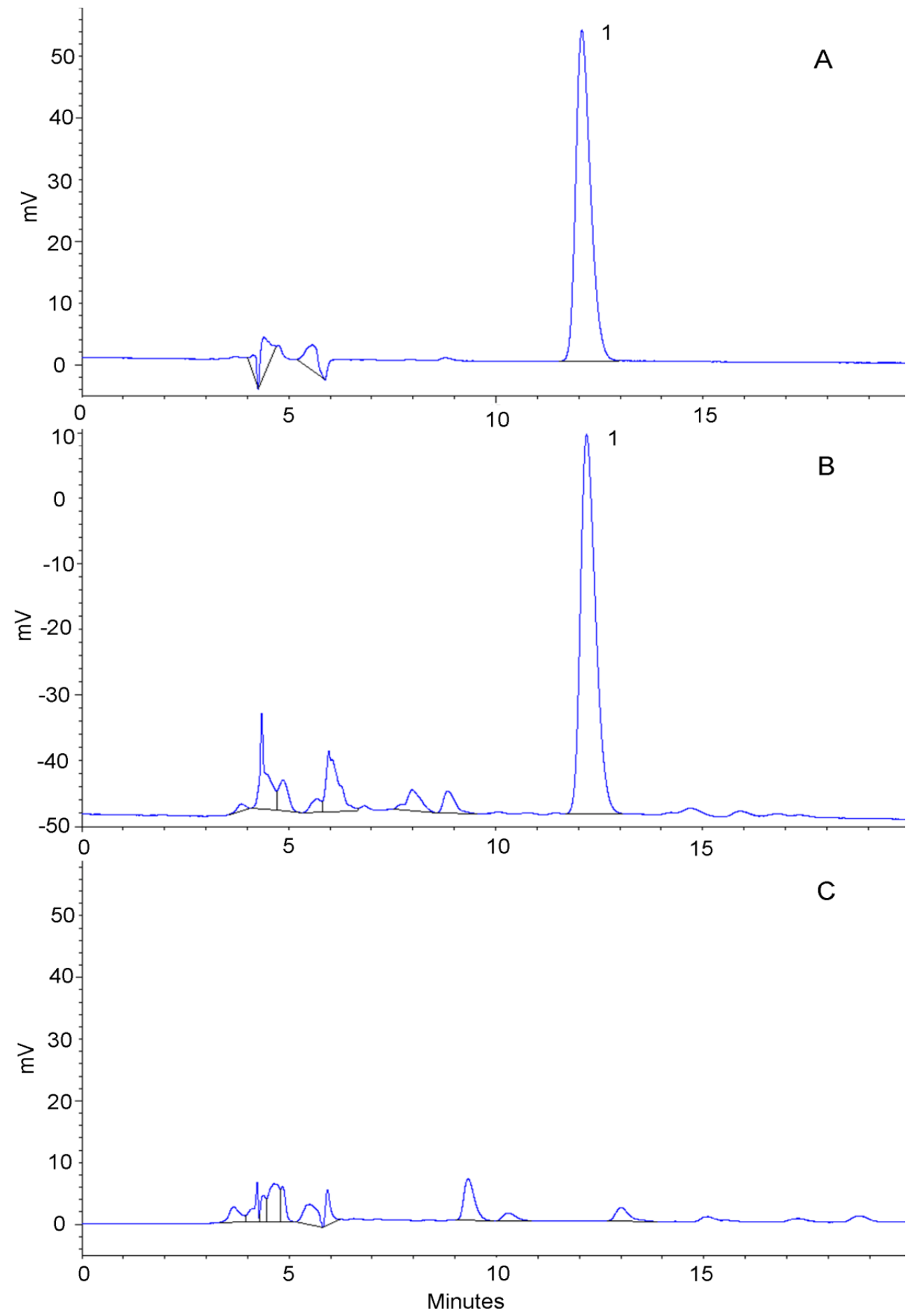

Figure 6. (A) HPLC of Geniposide reference solution; (B) HPLC of Tangkening granule test solution; (C) HPLC of negative solution. 1, Reference compound of Geniposide

are influenced by various factors. So in order to control the internal quality effectively, it is particularly important to ensure that the preparation is safe, effective and stable, and makes a scientific, rational and feasible quality standards.
F. gardeniae is the main drug in Tangkening granule, which is one of the main active constituents. The determination of $F$. gardeniae content has been extensively studied, and the main methods are TLC and HPLC. Many studies reported that geniposide has good 
Table 1. Analytical results of the recovery test.

\begin{tabular}{ccccc}
\hline Original amount $(\mathbf{m g})$ & Spiked amount $(\mathbf{m g})$ & Measured amount $(\mathbf{m g})$ & Recovery $(\%)$ & Average recovery $(\%)$ \\
\hline 1.6132 & 1.5225 & 3.1604 & 101.6 & - \\
1.9280 & 1.5225 & 3.4643 & 101.0 & - \\
1.9442 & 1.5225 & 3.4578 & 99.4 & 99.9 \\
1.7492 & 1.5225 & 3.2472 & 98.4 & - \\
1.7086 & 1.5225 & 3.2868 & 103.7 & - \\
1.7394 & 1.5225 & 3.1902 & 95.3 & - \\
\hline
\end{tabular}

Table 2. Assay results of geniposide in Tangkening granule (mg/g).

\begin{tabular}{lccc}
\hline Parameter & \multicolumn{3}{c}{ Value } \\
\hline Batch number & 0803001 & 0803002 & 0803003 \\
Content of geniposide & 6.67 & 6.71 & 6.91 \\
\hline
\end{tabular}

effect on reducing blood glucose. In this study, TLC was adopted to establish the identification of $F$. gardeniae, $H$. gynostemmatis, $D$. batatas, and HPLC was adopted to determine the content of geniposide in the preparation of Tangkening granule as the assay index. The results show that the method not only has good linear relationship $(r=$ 0.9999), high recovery $(99.90 \%)$, but also the precision test, stability test, and repeatability test all conform to the requirements of the analysis. Therefore, this method was very useful to evaluate the quality control and standardization of Tangkening granule.

\section{ACKNOWLEDGEMENT}

This study was supported by the special fund of modernization for traditional Chinese medicine of Zhejiang Province (No. 2006-164, Zhejiang Provincial Department of Finance).

\section{REFERENCES}

Guo Su-hua, Lin Zhu-can (2007). Studies on quality standard of Sedumaizoon L. China J. TCM Pharm. 22(11): 367-369.

Huang HL, Yang HJ, Liu LC (2006). Experimental studies on Fructus Gardeniae in decreasing blood sugar. Tradit. Chin. Drug Res. Clin. Pharmacol. 17(1): 1-3

Kimura Y, Okuda H, Arichi S (1982). Effects of geniposide isolated from gardenia jasminoides on metabolic alterations in high sugar dietfed rats (Tokyo). Chem. Pharm. Bull., 30: 4444-4447

Koo HJ, Song YS, Kim HJ, Lee YH, Hong SM, Kim SJ (2004). Antiinflammatory effects of genipin, an active principle of gardenia. Eur. J. Pharmacol., 495: 201-208.
Kuo WH, Wang CJ, Young SC, Sun YC, Chen YJ, Chou FP (2004). Differential induction of the expression of gst subunits by geniposide in rat hepatocytes. Pharmacology, 70: 15-22.

National Pharmacopoeia Committee (2005) China Pharmacopoeia (First subdivision). Beijing: Chem. Ind. Press, p. 173.

Normile D (2003). Asian medicine. The new face of traditional Chinese medicine. Science, 299: 188-90.

Park EH, Joo MH, Kim SH, Lim CJ (2003). Antiangiogenic activity of gardenia jasminoides. Fruit Phytother. Res., 17: 961-962.

Pham TQ, Cormier F, Farnworth E, Tong VH, Van Calsteren MR (2000). Antioxidant properties of crocin from gardenia jasminoides ellis and study of the reactions of crocin with linoleic acid and crocin with oxygen. J. Agric. Food. Chem., 48: 1455-1461.

Wu SY, Wang GF, Liu ZQ (2009). Effect of geniposide, a hypoglycemic glucoside, on hepatic regulating enzymes in diabetic mice induced by a high-fat diet and streptozotocin. Acta Pharmacol. Sin. 30(12): 202208.

Xu Xiao-wei, Pan Rou-he (2005). Content determination of geniposide in Qingkailing granules by RP-HPLC. Northwest Pharmaceut. J. 20(1): 9-10.

Xia DZ, Yu XF, Liao SP, Shao QJ, Mou HL, Ma W (2010). Protective effect of Smilax glabra extract against lead-induced oxidative stress in rats. J. Ethnopharmacol., 130: 414-420.

Yan JE, Li WC, Bian GX, Wen LQ, Ren JP (2007). Effect of geniposide on blood sugar reduction and its activation to PPARy receptor. J. Sichuan. Agric. Univ., 25: 415-418.

Zhang JW, Wang JH, Xu CC (2009). Studies on hypoglycemic activity and mechanism of Tangkening Granule. Acta Chin. Med. Pharmacol., 37(3): 16-18.

Zhang CY, Parton LE, Ye CP, Krauss S, Shen R, Lin CT (2006). Genipin inhibits ucp2-mediated proton leak and acutely reverses obesity- and high glucose-induced beta cell dysfunction in isolated pancreatic islets. Cell. Metab., 3: 417-427. 